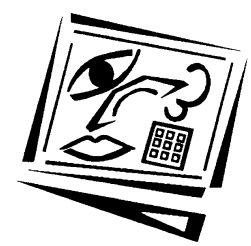

\title{
Exploring teacher knowledge and actions supporting technology-enhanced teaching in elementary schools: Two approaches by pre-service teachers
}

\author{
Candace Figg and Kamini Jaipal Jamani \\ Brock University
}

\begin{abstract}
Two approaches to teaching with technology to highlight practice-based teacher knowledge and actions for teaching technologically enhanced lessons are presented. Participants were two elementary pre-service teachers teaching during practicum. Qualitative data sources included verbatim transcripts of participant interviews, field notes of planning and support sessions, and classroom observations. Teacher lesson plans and student work samples triangulated data. Cross case analysis revealed that content-centric pedagogy - focusing lesson design on a specific content learning outcome, rather than technical skill - promoted student engagement and learning of both content and technical skill. Additionally, some pedagogical knowledge characteristics, reflected in specific teacher actions related to planning and implementation of technology-enhanced lessons, were fundamental across the two subject areas investigated. For novice elementary teachers, explicit communication of generic technology pedagogical knowledge characteristics, supported by concrete examples of teacher actions, may contribute to teachers experiencing a degree of success during their initial attempts at teaching with technology.
\end{abstract}

\section{Introduction}

The competent 21st century teacher no longer approaches teaching with technology using technocentric strategies and techniques (teaching the tool); they incorporate more content-centric approaches (teaching with the tool), focusing on students' curriculum with standards-based learning (Harris, Mishra \& Koehler, 2007; Jonassen, Howland, Marra \& Crismond, 2008). Teaching with the tools rather than teaching the tools allows teachers to see more quickly how the tools can be used to support learning. Incorporating this perspective into teaching and teacher education requires research that illustrates clearly and simply the "most effective ways to help teachers take advantage of technology" (Thompson \& Mishra, 2008, p. 38). One of these ways is to identify actions of teachers during teaching practice that support student learning of content knowledge and technical skill knowledge.

Few studies have investigated what these specific pedagogical actions are in relation to technology-enhanced lessons. Many studies have used self-report data from pre- and post surveys or pre- and post interviews to examine the use of technology in teaching by novice teachers, specifically pre-service teachers (Dexter \& Riedel, 2003; Doering, Hughes \& Huffman, 2003; Erickson, Jaipal, Mayer-Smith \& Westrom, 2003; Grove, Strudler \& Odell, 2004). Such data yielded general skills related to technology attitudes and technical competence, but did not describe what pre-service teachers do in 
practice. Grove et al. (2004) suggested that in order to further understand pre-service teachers' experiences with technology use in teaching, actual classroom observations as well as surveys and interviews are needed. A few recent studies have incorporated observations as well as interviews to document how pre-service teachers acquired, used, and shared knowledge during teaching practice, with support from each other and their associate teachers, leading to effective teaching with technology (MargerumLeys \& Marx, 2004; Schmidt, Baran, Thompson, Mishra, Koehler \& Shin, 2009; Sahin, Akturk \& Schmidt, 2009; Cox \& Graham, 2009).

Case studies of technology-enhanced classroom practice provide insights and understandings about the types of knowledge teachers need to effectively teach with technology. This paper presents two case studies of pre-service teachers teaching with technology to identify characteristics of teacher knowledge and specific teacher actions supporting student engagement and learning during technology-enhanced lessons. The findings contribute to: 1) the literature by identifying characteristics of technological pedagogical knowledge supporting technology-enhanced lessons, and 2) the practices of pre-service and in-service teachers, and teacher educators by providing concrete examples of teacher actions in classroom practice that support and impede technology-enhanced teaching and learning.

\section{Teacher knowledge for teaching with technology}

Pre-service teachers require more than knowledge of technical skills in order to promote meaningful learning (Jonassen, Howland, Marra \& Crismond, 2008). Shulman (1986) suggests that meaningful student learning of content occurs when teachers demonstrate a strong understanding of the relationship between content and pedagogical knowledge - one that "goes beyond knowledge of subject matter per se to the dimension of subject matter knowledge for teaching" (p. 9), or pedagogical content knowledge (PCK). Shulman (1987) further explains that PCK "represents the blending of content and pedagogy into an understanding of how particular topics, problems, or issues are organized, represented, and adapted to the diverse interests and abilities of the learners, and presented for instruction" (p. 8).

Shulman's (1986) model of teacher knowledge is situated within subject matter disciplines, such as science, language arts, or math. In this model, technology is regarded as an add-on to the content instruction - a part of what is known as curriculum knowledge. According to Shulman (1987), curriculum knowledge refers to knowledge of the "materials and programs that serve as 'tools of the trade' for teachers"' (p. 8).

However, Koehler and Mishra (2008) suggest that knowledge of how to teach with technology should be regarded as a distinct component of teacher knowledge, describing this knowledge as an understanding that emerges from an interaction of content, pedagogy, and technology, referred to as Technological Pedagogical Content Knowledge (TPACK) [1]. (Koehler \& Mishra, 2008, p. 12). TPACK is complex and influenced by multiple factors within and outside the school context (Zhao, et al., 2002; Ertmer, Addison, Lane, Ross \& Woods, 1999). This paper limits its scope and explores the technology knowledge components of the TPACK model (Technological Knowledge [TK], Technological Content Knowledge [TCK], and Technological Pedagogical Knowledge $[\mathrm{TPK}])$. 
Technological knowledge (TK) is characterised by individuals' understanding of technology "broadly enough to apply it productively at work and in their everyday lives, to recognise when information technology can assist or impede the achievement of a goal, and to continually adapt to changes in information technology" (Koehler \& Mishra, 2008, p. 15). TK, as applied in this study, includes aspects of understanding and mastery of technology (technical skills) and application of those skills in productive ways in everyday use (competent personal use with the tools).

Koehler and Mishra (2008) define Technological Content Knowledge (TCK) as:

an understanding of the manner in which technology and content influence and constrain one another. ... Teachers need to understand which specific technologies are best suited for addressing subject matter learning in their domains and how the content dictates or perhaps changes the technology - or vice versa (p. 16).

In this study, TCK was conceptualised as the demonstration of the ability to match the technology tools to achieve specific subject matter content goals or learning outcomes. For example, if the learning goal is to conduct an inquiry project in science, then graphing software is an appropriate tool to facilitate data analysis.

Technological Pedagogical Knowledge (TPK) is "an understanding of how teaching and learning changes when particular technologies are used which includes knowing pedagogical affordances and constraints of a range of technological tools as they relate to disciplinarily and developmentally appropriate pedagogical designs and strategies" (Koehler \& Mishra, 2008, p. 16). TPK, as formulated for this study, is defined as the effective use of technology to plan and implement lessons that achieve the subject matter instructional goals; it is characterised by practical teaching competencies (i.e., instructional design, classroom management, organisation, evaluation, differentiated instruction) during planning and implementation of technology-enhanced lessons.

\section{Research methods}

\section{Participants and setting}

The two case study participants (pseudonyms 'Sandra' and 'Chelsea') were pre-service teachers in an 8-month BEd program, representing a purposive sample of pre-service teachers in the program. Criteria for participation included a keen interest in learning how to integrate technology into classroom teaching, and placement at an elementary school within the researchers' allotment area. In addition, having associate teachers who expressed an interest in allowing the pre-service teachers under their supervision to teach with technology was also a consideration. The two participants were in two different elementary schools from similar socio-economic areas. A research team of two university researchers, one research assistant, and the technology specialist for the school board worked with each participant to provide 'just-in-time' technical and pedagogical support to encourage pre-service teachers to enhance their lessons using technology.

\section{Data sources}

Qualitative data sources included a background questionnaire, transcripts of individual interviews, planning and support sessions, observations of classroom teaching (two to three per participant), and post lesson debriefing interviews. Teacher 
artefacts, such as lesson plans and anonymous student work samples, were also collected. The number of support sessions for each participant varied, based on participants' needs.

\section{Procedure}

During the first week of the 7-week practicum (March), the research team, including the technology specialist, conducted a mini-workshop brainstorming session with the pre-service teachers to make decisions about the integration of technology in their lessons. Further assistance in lesson designing and implementation was provided on site as requested, including a variety of supports - cycles of feedback on lesson planning, technology resources and laptops, one-on-one technical instruction, and additional assistance in the computer lab during lesson implementation. An online communication management tool, Gaggle (https://gaggle.net/), was used to create a support forum where technical tutorials and other relevant information were posted. Technology-enhanced lessons were then observed, followed by post-lesson debriefing interviews. Individual interviews with the pre-service teachers were conducted during the final week of the practicum.

\section{Data analysis}

Factors previously identified in the research as influencing technology integration, including time, access to resources, technology infrastructure, and technical support staff (Becker, 1994; Hadley \& Sheingold, 1993; Zhao, Pugh, Sheldon \& Byers, 2002), and other multiple factors interacting within and outside the school context (Zhao et al., 2002; Ertmer, Addison, Lane, Ross \& Woods, 1999), were mediated as much as possible through offers of 'just-in-time' training for technical (TK), and subject matter knowledge (CK), to allow participants to focus on planning and implementation of subject matter content with technology (TK, TCK and TPK).

Therefore, transcripts of planning sessions, post-lesson debriefing sessions, classroom observations, and individual interviews were coded with a focus on planning and implementation strategies and techniques. Two researchers coded the data independently to generate emergent themes across cases (Yin, 2008; Miles \& Huberman, 1994). Key descriptor phrases of teacher actions were aggregated and categorised into general coding categories or themes. From the general coding categories identified from the data, characteristics were identified and sorted into the three technology components TK, TPK and TCK as described by Koehler \& Mishra (2008) and operationalised by the authors in Table 1 (Figg \& Jaipal, 2009).

Table 1: Operationalised definitions of the three technology knowledge components of TPACK: TK, TCK, and TPK

\begin{tabular}{|l|l|}
\hline $\begin{array}{l}\text { Technological Knowledge } \\
\text { (TK) }\end{array}$ & Technical skills plus competent personal use with the tools \\
\hline $\begin{array}{l}\text { Technological Content } \\
\text { Knowledge (TCK) }\end{array}$ & $\begin{array}{l}\text { Ability to match the technology to the subject matter content to } \\
\text { achieve specific subject matter goals or learning outcomes }\end{array}$ \\
\hline $\begin{array}{l}\text { Technological Pedagogical } \\
\text { Knowledge (TPK) }\end{array}$ & $\begin{array}{l}\text { Practical teaching competencies (i.e., classroom management, } \\
\text { organisation, evaluation, differentiated support resources, accomm- } \\
\text { odating prior knowledge during planning and implementation) }\end{array}$ \\
\hline
\end{tabular}

The two cases in this paper are presented thematically to highlight teacher actions associated with planning and implementation approaches. The three thematic 
categories that emerged from the cross-case analysis were: 1) comfort level and attitude towards using technology (TK), 2) planning approaches (TCK \& TPK), and 3) implementation approaches (TPK). Assertions are supported by excerpts from the questionnaire, transcripts, and teacher artefacts. Classroom observation data and student artefacts are used as evidence to describe the influence of these teacher actions on student engagement and learning.

A limitation of this study is that we present data from two cases of pre-service teachers teaching with technology. However, it is not our intention to make generalisations to other populations, but to provide insights and understandings about pre-service teacher actions in teaching with technology. Additional case studies are needed to expand or extend findings.

\section{The thematic cases}

\section{Comfort level and attitude toward using technology}

\section{Sandra}

Sandra was apprehensive about introducing technology into classroom practice but was eager to learn. She had completed a short teacher education methods course in using technology in the classroom and had some ideas about appropriate places to integrate the technology, but she viewed her skill level as beginning and indicated a low comfort level with computer tools. Her practicum placement was in a Grade 8 Social Studies class with 27 students, and she sought suggestions from her associate teacher about an appropriate unit that she could design and teach. Her associate teacher suggested she teach a unit that would satisfy the curriculum area of Application of Geographic Economic Systems and provided her with subject matter resource materials. These resource materials provided a series of lessons that required students to create a "lunchable," a boxed lunch product, which could be marketed. Sandra brought these materials to the brainstorming session and asked specific questions about how she could use technology to promote the selected curriculum goals.

\section{Chelsea}

Chelsea was comfortable talking about technology. She had completed the technology in the classroom course, and she indicated that she was somewhat comfortable with computer tools and rated herself as fairly proficient with the tools. Her practicum placement was in a Grade 4 class with 34 students. Chelsea had no clear ideas about where she would integrate technology into the curriculum. She used the brainstorming during the planning session to talk about topics she would be teaching and listened intently to the discussions and suggestions of the technology specialist. After the brainstorming session, she decided to teach students how to use KidPix, a children's software tool for drawing objects on individual slides that can be displayed as a slideshow. She selected Endangered Species as the topic for the slideshow, a topic within the Grade 4 Ontario Science unit on Habitats and Communities.

\section{Planning approaches}

Sandra

Sandra approached the planning of her technologically-enhanced lessons as a collaborative learning process. She used the ideas from the initial brainstorming sessions, and commented: 
I wouldn't have thought of using SMART Ideas and Audacity because I'd never heard of them before in my life!

She followed up with many meetings with the research team and technology specialist prior to lesson design, soliciting ideas and bouncing ideas off of the more experienced team members and listening to suggestions and comments about how to incorporate SMART Ideas and Audacity into her lessons. She then incorporated many of the ideas in the lesson designs and forwarded them to the research team or her associate for feedback and suggestions. Her series of lesson plans on Economic Systems was developed in collaboration with the research team through this cycle of working independently to put her ideas into the lesson, then soliciting feedback as to how to improve the lesson. During these cycles of feedback, issues such as how to use specific tools (NetSupport, Audacity and SMART Ideas [2]) would arise. Sandra would then arrange to receive one-on-one, 'just-in-time' training in new or different tools. She explained:

I got a tutorial [on using NetSupport] in less than 10 minutes -- someone sits down with me and then we open it up and they show me an example.

Afterwards, she practised using the tools by herself, often seeking additional tutorials and exercises through online sources, and then practised using the tool with the computers in the lab.

In addition, Sandra approached planning as a process in which learning activities were sequenced in lessons to promote the content learning outcome (content-centric). For example, she designed a series of lessons where students first researched the resources that were used to make the ingredients of the lunchable products that would be included in a lunchable of their own design. In Lesson 2, students created a pencil and paper graphic organiser to show the manufacturing steps to produce the ingredients (e.g., corn was ground into flour, which was in turn used to make tortillas). In Lesson 3, students used SMART Ideas to create a complex concept map of the manufacturing processes used to make all ingredients in their lunchable. Lesson 4 involved creating an advertisement that could be used to market their lunchable. Students drew a picture of the lunchable, creating an appropriate slogan or jingle for their lunchable, and then recorded the advertisement/jingle as a podcast. As a culminating activity, students presented their products and advertisements to classmates.

Once Sandra had completed the instructional design, she then considered the pedagogical aspects of implementing the lesson, including learner prior experiences and knowledge. Many of the grade 8 students had used SMART Ideas before; nevertheless, she still created a simple handout (See Appendix A) for her students to serve as a guide for creating a flowchart using SMART Ideas. Using a handout also enabled Sandra to provide differentiated supports for varying student levels of technical and reading skills.

As part of her implementation, Sandra also created her own exemplar of a flowchart on SMART Ideas that could be used to model expected student outcomes (see Appendix B). She planned to use NetSupport to demonstrate how to create a flowchart in SMART Ideas, describe the expected student product using her exemplar, and then facilitate student activity as they worked through the short handout. So, her overall focus in this unit design was on the content learning outcome (content-centric), not technical skill learning. 


\section{Chelsea}

Chelsea did not indicate any personal preferences about how she wanted to use technology in her instruction when she arrived at the brainstorming session with the research team. She found the suggestion to use KidPix exciting and decided students could use the tool to conduct research on habitats for a Grade 4 Science unit. Therefore, she chose to design a series of lessons on creating a slideshow on endangered species, a topic that students were completing with her associate teacher. She designed two lessons - Lesson 1 focused on researching the endangered animal and Lesson 2 on creating the slideshow.

Chelsea approached the planning process as an independent task. She did not follow up with the research team during the planning phase of the lesson involving KidPix; she only sought feedback on her lesson plan and rubric from her associate teacher, an experienced teacher of science.

I wrote it up. I did the actual written instructions for the students, and did the rubric at the end.

In her interview, Chelsea stated that her focus was not on the science learning outcomes, but she wanted her students to learn how to use KidPix. Hence, her lesson was designed to build technical skills (techno-centric).

So basically it was the technical part of it - I just wanted them to know how to do the slideshow.

As with Sandra, Chelsea realised that she needed to improve her own technical skills using KidPix. She was somewhat confident in her own ability to work with computers, and she practiced using KidPix at home on her own computer.

I just went in there and I kind of fiddled around myself to see what worked and didn't. I didn't really use the "Help" thing! That's the way we learn to use computers now!

Chelsea felt that the way to teach the students how to use KidPix would be to take all of the students into the computer lab and guide them through the steps needed to create a slideshow.

I was going to do it step-by-step. "Go to KidPix" then "Add Graphics" as a group.

Therefore, she created materials to support this type of teacher-directed activity, including an exemplar of the expected finished student product (see Appendix C), a detailed handout (see Appendix D) providing steps for completing technical skills, and a handout (see Appendix E) outlining the science content for each slide. She planned to demonstrate each step of the technical handout, and then have students work through the steps independently to create their slideshow while she assisted those students needing additional help.

\section{Implementation approaches}

\section{Sandra}

Sandra began her lesson by instructing students that they would be designing a lunchable product with ingredients that could be acquired from economic resources in the surrounding geographic regions. She directed the students to do the following: 
I want you to organise your ideas about the items in your lunchables — which resource and country do the items come from?

Sandra's comment showed that the focus of the lesson was not on learning the technology tool (SMART Ideas), but was on learning the subject matter outcomes. Students would determine the needed ingredients for the lunchable they were designing and locate the source of the resources. During Lesson 1, students conducted research in books to locate this information. In Lesson 2, Sandra modeled how to construct a brainstorming web to display that information. She drew a web example of what they would be constructing on the blackboard. Students then used pencil and paper to draft out their webs for their lunchables. An example of a student-created concept map is illustrated in Figure 1.

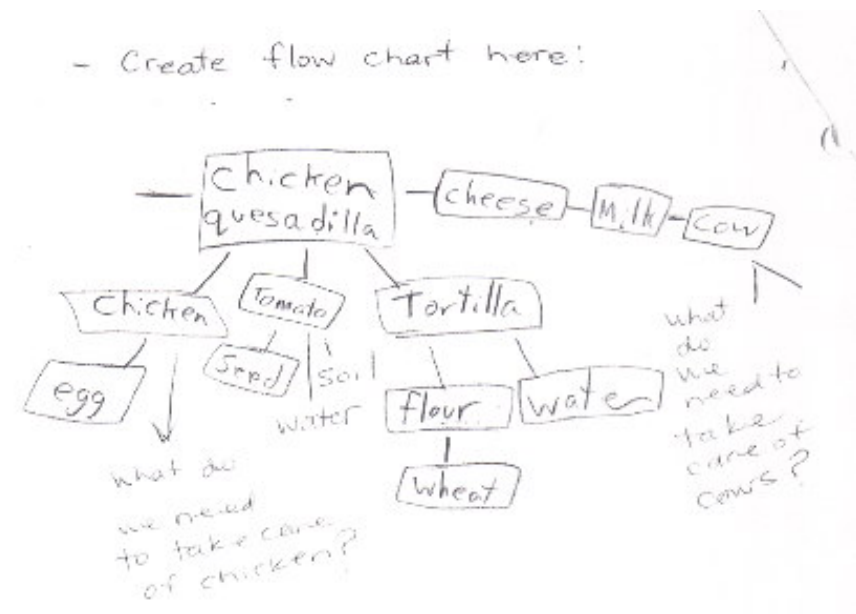

Figure 1: Hand-drawn student web.

In Lesson 3, Sandra prepared students to work in the lab by providing directions for behaviour expectations, and then walked her students to the lab. She told her students that she would demonstrate creating a flowchart using SMART Ideas. They would next use the tool to create their own flowchart for their lunchable. Sandra turned on NetSupport, a network management tool that displayed what was on her teacher monitor to all the computers in the lab and, at the same time, froze student keyboards. She briefly demonstrated four skills: creating symbols, linking symbols, adding labels, and formatting symbols for color/clarity. She provided the students with the short printed handout (see Appendix A) for reference and then turned NetSupport off so students could begin working on their own flowcharts. Students were fully engaged in the learning activity and generated more complex flowcharts than their paper drafts as illustrated in Figure 2.

In Lesson 4, Sandra instructed students to design packaging for their lunchables and create slogans and/or short advertisements to be recorded as podcasts. Prior to Lesson 5, Sandra requested technical support from the researchers and the technology specialist to set up and test the headphones so that equipment would be operating properly. In Lesson 5 she demonstrated the use of Audacity to record a podcast, and then her students worked in pairs to record their slogans or advertisements as podcasts. 


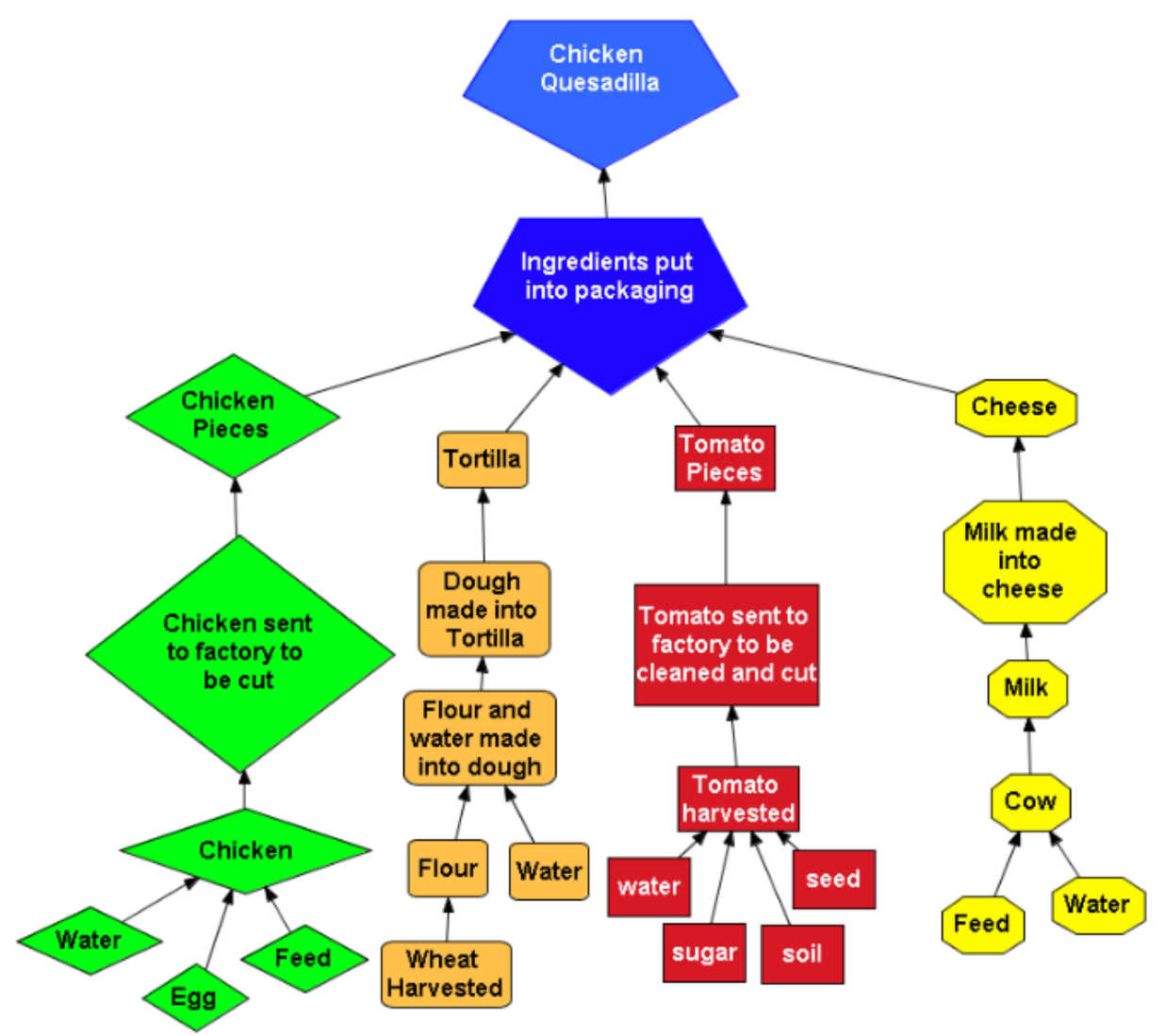

Figure 2: Computer-generated student flowchart

Chelsea

Chelsea used a different style for implementing her lessons. She took her Grade 4 students to the computer lab where she began the first lesson by showing her students a paper example of the finished product they would be constructing. Students, guided by a set of questions and teacher assistance, worked independently to conduct Internet research to locate pictures and information on an endangered animal of their choice. Pictures were bookmarked and relevant information recorded on the worksheet.

In the follow up, double lesson period, in the computer lab, Chelsea's lesson goal was to have students create the actual KidPix slideshow consisting of 5 slides. Each slide would contain one piece of researched information about an endangered animal and any appropriate pictures collected in the prior lesson. Students were provided with a two-page technical skill handout (see Appendix D) and she began reading the directions for Step 1, which was on importing pictures. Chelsea expected her students to listen to her directions or read the directions and then carry out the step. However, many students had difficulty accessing folders with pictures and importing pictures from folders. Students also worked at different rates; some were able to follow the directions without assistance and others had difficulty and required one-on-one help. Chelsea responded to what was happening by making changes in her lesson plan on the fly, hoping to help students more clearly understand what to do. She spent the 
entire one hour lesson assisting students individually to import pictures into KidPix. Five out of the 34 students were able to begin creating slides; only one student was able to build all five slides similar to the example. When Chelsea reflected on the lesson during her interview, she commented:

It just didn't work because some were faster than others; some were slower than others so that's when I decided to use NetSupport next time... the lower kids got frustrated really easily and they were the ones that quit right away!

Chelsea further explained that she had never thought that the variance in the skill levels of the students would present difficulty because she would be walking them through step by step. For her next lesson, she reduced the number of technical instructions to six (see Appendix D), she asked the technology support teacher at the school to show her how to use NetSupport, and she practiced using NetSupport so that she could control the presentation and demonstrate the six steps she had decided to use. Further revision and completion of the instructional cycle was not possible due to difficulties in scheduling time in the computer lab in the short time remaining for the practicum.

\section{Cross-case analysis}

While the two cases highlight many aspects of content and pedagogical knowledge, we focus on teacher knowledge pertaining to the effective use of technology. The crosscase analysis of two pre-service teachers' approaches to teaching with technology highlighted characteristics of technological pedagogical content knowledge (TPACK) in the planning and implementation phases of teaching.

\section{Characteristics of teacher knowledge during planning of technology-enhanced lessons}

Teacher knowledge influencing the planning of technologically enhanced lessons was related to: 1) content-centric learning goals for the lesson, 2) choice of technologyenhanced activity, 3) differentiation strategies, and 4) sequencing of activities.

With regard to learning goals for the lesson, the findings of the current study suggest that content-centric goals supported student learning of content and technical skills Sandra's students were able to meet social studies learning outcomes though technologyenhanced activities - they learned technical skill and content knowledge. Chelsea's focus on teaching the technology skill (making a slideshow) and using the content as the medium was not as effective at engaging students in technical skill and content learning. Pre-service teachers' choice of activity included the actions of soliciting advice about selection of technology activities. The findings suggest that for novice teachers, soliciting constant feedback from experienced teachers in both technology and subject matter content (e.g., technology consultant and associate teacher) on the appropriateness of the technology activity to support the subject matter learning outcomes, is more beneficial than planning independently or receiving feedback on the lesson design in relation to the content only.

Both pre-service teachers' planning actions reflected ways to differentiate and sequence technology-enhanced activities for student learning. Two teacher actions that were significant for student engagement and learning in these technology-enhanced lessons were: 1) preparing brief handouts, and 2) sequencing the lessons to introduce a few 
technical skills at a time with the content. Chelsea's technology-enhanced lesson was initially designed to introduce all skills (in a 2-page handout) and incorporate science content in a double period lesson. She later modified the handout to a few simple instructions to teach a few select technical skills. This modification suggests that novice teachers require support in how to sequence technology activities if they wish to maximise student engagement and the learning of technical skills and subject matter content during the lesson.

\section{Characteristics of teacher knowledge during implementation of technology- enhanced lessons}

Teacher knowledge influencing the implementation of technologically enhanced activities was related to: 1) preparation for the teaching act, 2) knowledge of specific classroom management techniques for teaching with technology, and 3) modeling strategies.

Specific teacher actions related to preparation for the teaching act that emerged as significant for student engagement and learning included: 1) training to use software applications, 2) practising in the computer lab prior to the lesson, and 3) planning back-up activities. For example, Sandra prepared for the teaching act by physically going to the lab and rehearsing how she would demonstrate and model what she wanted the students to do. In this way, she was able to modify and plan for unforeseen technical difficulties that could arise during implementation. She found that she needed additional headphones and technical assistance in setting up the lab for podcasting, and was able to recruit the experienced teachers' help for this section of the lesson. Chelsea prepared for the teaching by training on the software and by working out her delivery scenario mentally at her computer at home. However, the additional action of practising in the lab may have minimised some of the technical difficulties that arose because of her unfamiliarity with the configuration of a different set of computers in the lab.

With regard to management strategies during computer-supported lessons, the two cases showed that demonstrating technical skills using NetSupport facilitated student engagement and minimised management issues. Sandra used NetSupport to focus student attention on her demonstration and instructions by displaying her screen on each student's computer monitor. A second effective strategy to engage and motivate students was the use of appropriate grouping techniques by the teacher to scaffold learning. This strategy served to provide support to students in learning the content and/or using the technology. Sandra grouped students (2 students at a computer), matching technical and academic learning needs to facilitate a successful learning experience for students. Chelsea's lesson could have been more successful if she had grouped her Grade 4 students to complement each other's learning and technical skills needs, thus allowing her students to work collaboratively to complete the task (the slideshow), and this would have given her more time to monitor and assist students experiencing additional challenges.

Various modelling strategies were used successfully in the two cases. The use of written examples, blackboard examples, and computer-demonstrated examples to model for students an expected outcome of the lesson facilitated student learning by providing additional scaffolds during the lesson. 


\section{Discussion and conclusion}

Teaching with technology that results in meaningful learning for students occurs when teachers demonstrate strong teacher knowledge of more than just technical skills (Jonassen, Howland, Marra \& Crismond, 2008). The two case studies suggest that knowledge of content-centric pedagogy - focusing lesson design on a specific content learning outcome rather than the technical skill — promotes meaningful student learning of both content and technical skill, which is similar to other findings in the literature (Harris, Mishra \& Koehler, 2007).

Mishra and Koehler (2008) point out that effective teaching with technology requires knowledge of pedagogy, content, and technology. Current literature (Hughes \& Scharber, 2008; McCrory, 2008; Niess, 2005) also suggests that each content area has specific technology skills that are unique to that discipline. This literature has identified characteristics of Technological Pedagogical and Content Knowledge (TPACK) in relation to different subject areas, including science, math, social studies, and language arts. Our findings point to the idea that there are some technology pedagogical skills that are fundamental for teaching with technology across all subject areas for elementary teaching. Specific characteristics of teacher actions related to planning and implementation of technology-enhanced lessons across subject areas were identified. Characteristics of planning included: 1) content-centric goals for lesson, 2) choice of technology-enhanced activity, 3) differentiation strategies, and 4) sequencing of activities. Implementation characteristics included: 1) preparation for the teaching act, 2) knowledge of specific classroom management techniques for teaching with technology, and 3) modeling strategies.

While these characteristics are similar to general pedagogical knowledge that teachers draw on for teaching, they are unique in how they are expressed by teacher actions in the classroom during technology-enhanced lessons. For example, all teachers differentiate for student learning when they plan their lessons. However, a different set of differentiation strategies as represented by teacher actions is required for a technology-enhanced lesson. As was shown in the case studies, appropriate differentiation of handouts to support both content and skill development was necessary. Grouping students would also involve knowledge of student technical skill abilities, as well as content knowledge or academic skill level and knowledge of the number of students to maximise engagement and learning.

In order for novice teachers to become comfortable using technology in their daily classroom practice, they need to have successful experiences with their initial technology-enhanced teaching experiences, as teachers tend to repeat strategies that they perceive as successful. The case of Chelsea shows that knowledge of these strategies and teacher actions may not come naturally to all pre-service teachers; often, these actions are not intuitive and are learned through 'just-in-time' mentoring (provided to participants in this study by the team of researchers and associate teachers). The latter observation is consistent with notions of learning TPACK skills through technology mentoring in the literature (Figg \& Jaipal, 2009). Hence, there is a need to explicitly identify what this TPACK knowledge looks like in practice (TPACK-inpractice). Such explicit knowledge is pertinent for technology teacher educators, subject matter methods teacher educators, and associate teachers who mentor preservice teachers, as it highlights specific technological pedagogical and content knowledge used in practice that is generic across different subject content areas. 
This study begins to identify some of these generic explicit strategies and actions that represent TPACK-in-practice and can be incorporated into the technology methods courses, or integrated into subject based methods courses in teacher education programs. Some instructor-guided strategies are:

- Illustrating to pre-service teachers how to create a technology tutorial (either print or electronic) appropriate for different grade levels, and demonstrating how to group students in the computer lab to provide technical and academic scaffolding.

- Introducing pre-service teachers to a variety of technology tools that support learning activities, such as using Inspiration, SMART Ideas, or Popplet, to brainstorm or flowchart. This supports pre-service teachers in the development of a repertoire of technology-enhanced activities that they can use in their lesson designs; they also learn specific TPACK-in-practice actions, such as how to sequence the teaching of technical skills with the focus on content learning.

- Participating in an instructor-modelled technology-enhanced learning activity as learners that highlight different TPACK-in-practice strategies and techniques. [3]

Pre-service teachers then take on the role of the teacher in simulated teaching situations that incorporate student-centred or collaborative learning, including:

- Peer teaching of technology-enhanced activities within small groups,

- Critiquing effectiveness of TPACK-in-practice of a video recorded mini-lesson,

- Critiquing of case studies or video cases of technology-enhanced instruction.

Incorporating these generic TPACK-in-practice skills into teacher education and inservice courses provides pre-service teachers with practical knowledge to encourage successful lesson experiences during their first attempts at teaching with technology. Future research can expand or extend the current research by identifying other characteristics and actions of TPACK-in-practice that support successful technologyenhanced teaching.

\section{Endnotes}

1. TPCK was renamed TPACK to emphasise "the three kinds of knowledge (Technology, Pedagogy, and Content)" and the notion that "they form an integrated whole, a 'Total PACKage' as it were, for helping teachers take advantage of technology to improve student learning" (Thompson \& Mishra, 2008, p. 38).

2. NetSupport is a software application that allows the teacher to control all computers networked in a lab setting. Chelsea was able to demonstrate her example on all computers so students could follow along. More information is available at: http:/ / netsupport-inc.com/. Audacity is a free, audio editing software that allows students to record podcasts. More information is available at http:/ / audacity.sourceforge.net/. SMART Ideas is the brainstorming software application that allows users to create flowcharts, webs, or mindmaps. More information is available at: http:/ / smarttech.com/us / Solutions/Education+ Solutions/Products+for+education/Software/SMART+Ideas+software 
3. A more detailed discussion on how TPACK-in-practice is integrated into a technology course is provided at http:/ / www.handy4class.com

\section{References}

Becker, H. J. (1994). How exemplary computer-using teachers differ from other teachers: Implications for realizing the potential of computers in schools. Journal of Research on Computing in Education, 26(3), 291-321.

http:/ / www.citejournal.org/vol1/iss2/ seminal/article1.htm

Bracewell, R. J., Sicilia, C., Park, J. \& Tung, I. (2007, April). The problem of wide-scale Implementation of effective use of information and communication technologies for instruction: Activity theory perspectives. Paper presented at the 2007 Annual Meeting of the American Educational Research Association (AERA), Chicago, IL.

Cuban, L., Kirkpatrick, H. \& Peck, C. (2001). High access and low use of technologies in high school classrooms: Explaining an apparent paradox. American Educational Research Journal, 38(4), 813-834. http: / / www.jstor.org/ stable/3202504

Dexter, S. \& Riedel, E. (2003). Why improving preservice teacher educational technology preparation must go beyond the college walls. Journal of Teacher Education, 54(4), 334-346. http: / / dx.doi.org/10.1177/0022487103255319

Doering, A., Hughes, J. \& Huffman, D. (2003). Preservice teachers: Are we thinking with technology. Journal of Research on Technology in Education, 35(3), 342-361.

Erickson, G., Jaipal, K., Mayer-Smith, J., Nicol, C. \& Westrom, B. (2003). A faculty study of technology practices - understanding pre-service teachers' competencies and attitudes to learning technologies. Paper presented at the meeting of the 2003 Canadian Society for the Study of Education (CSSE), Halifax, NS.

Ertmer, P. A. (2005). Teacher pedagogical beliefs: The final frontier in our quest for technology integration. Educational Technology Research and Development, 53(4), 25-39. http: / / dx.doi.org/10.1007/BF02504683

Ertmer, P. A., Addison, P., Lane, M., Ross, E. \& Woods, D. (1999). Examining teachers' beliefs about the role of technology in the elementary classroom. Journal of Research on Computing in Education, 32(1), 54-71.

Figg, C. \& Jaipal, K. (2009). Unpacking TPACK: TPK characteristics supporting successful implementation. In I. Gibson et al. (Eds.), Proceedings of Society for Information Technology $\mathcal{E}$ Teacher Education International Conference 2009 (pp. 4069-4073). Chesapeake, VA: AACE. http: / / editlib.org/p/31295

Grove, K., Strudler, N. \& Odell, S. (2004). Mentoring toward technology use: Cooperating teacher practice in supporting student teachers. Journal of Research on Technology in Education, 37(1), 85-108.

Hadley, M. \& Sheingold, K. (1993). Commonalities and distinctive patterns in teachers' integration of computers. American Journal of Education, 101(3), 261-315. http: / / www.jstor.org/ stable/1085516

Harris, J. B., Mishra, P. \& Koehler, M. J. (2007). Teachers' technological pedagogical content knowledge: curriculum-based technology integration reframed. Paper presented at the 2007 Annual Meeting of the American Educational Research Association (AERA), Chicago, IL. http: / / mkoehler.educ.msu.edu /OtherPages / Koehler_Pubs/TECH_BY_DESIGN/AERA_20 07/AERA2007_HarrisMishraKoehler.pdf 
Hughes, J. \& Scharber, C. M. (2008). Leveraging the development of English TPCK within the deictic nature of literacy. In AACTE Committee on Innovation and Technology (Ed.), Handbook of Technological Pedagogical Content Knowledge (TPCK) for educators. New York: Routledge.

Jaipal, K. \& Figg, C. (2010). Unpacking the "Total PACKage": Emergent TPACK characteristics from a study of pre-service teachers teaching with technology. Journal of Technology and Teacher Education, 18(3), 415-441. http: / / www.editlib.org/p/ 28335

Jonassen, D., Howland, J., Marra, R. \& Crismond, D. (2008). Meaningful learning with technology. Upper Saddle River, NJ: Pearson.

Karsenti, T., Brodeur, M., Deaudelin, C., Larose, F. \& Tardif, M. (2002). Integrating ICTs in teacher training: A challenging balance. Paper prepared for the Pan-Canadian Educational Research Agenda Symposium, Montreal, QC. http: / / www.cesc.ca/ pceradocs/2002/ papers / TKarsenti_TEN.pdf

Koehler, M. J., \& Mishra, P. (2008). Introducing TPCK. In AACTE Committee on Innovation and Technology (Eds.), Handbook of Technological Pedagogical Content Knowledge (TPCK) for educators. New York: Routledge.

Margerum-Leys, J. \& Marx, R. W. (2004). The nature and sharing of teacher knowledge of technology in a student teacher/mentor teacher pair. Journal of Teacher Education, 55(5), 421437. http:/ / dx.doi.org/10.1177/0022487104269858

McCrory, R. (2008). Science, technology, and teaching: The topic-specific challenges of TPCK in science. In AACTE Committee on Innovation and Technology (Ed.), Handbook of Technological Pedagogical Content Knowledge (TPCK) for educators. New York: Routledge.

Miles, M. B. \& Huberman, M. (1994). Qualitative data analysis: An expanded sources book. Thousand Oaks, CA: Sage Publications.

Niess, M. L. (2005). Preparing teachers to teach science and mathematics with technology: Developing a technology pedagogical content knowledge. Teaching and Teacher Education, 21(5), 509-523. http: / / dx.doi.org/10.1016/j.tate.2005.03.006

Sahin, I., Akturk, A. \& Schmidt, D. (2009). Relationship of preservice teachers' technological pedagogical content knowledge with their vocational self-efficacy beliefs. In C. Crawford et al. (Eds.), Proceedings of Society for Information Technology and Teacher Education International Conference 2009 (pp. 4137-4144). Chesapeake, VA: AACE. http:/ / editlib.org/p/31307

Schmidt, D., Baran, E., Thompson, A., Mishra, P., Koehler, M. \& Shin, T. (2009). Examining preservice teachers' development of technological pedagogical content knowledge in an introductory instructional technology course. In C. Crawford et al. (Eds.), Proceedings of Society for Information Technology and Teacher Education International Conference 2009 (pp. 41454151). Chesapeake, VA: AACE. http:/ / editlib.org/p/31308

Shulman, L. S. (1986). Those who understand: Knowledge growth in teaching. Educational Researcher, 15(2), 4-14. http:/ / dx.doi.org/10.3102/0013189X015002004

Thompson, A. \& Mishra, P. (2008). Breaking news: TPCK becomes TPACK! Journal of Computing in Teacher Education, 24(2), 38. [verified 16 Nov 2011] http: / / punya.educ.msu.edu/publications/journal_articles/jcteeditorial-24-2-038.pdf

Yin, R. K. (2008). Case study research: Design and methods. Thousand Oaks, CA: Sage Publications.

Zhao, Y., Pugh, K., Sheldon, S. \& Byers, J. (2002). Conditions for classroom technology innovations. Teachers College Record, 104(3), 482-515. http: / / www.tcrecord.org/Content.asp?ContentId=10850 


\section{Appendix A: Sandra's lesson - lesson handout}

\section{Smart Ideas 5 Tutorial}

1. Using your mouse select Start at the bottom left hand corner of your screen, and click on Smart Ideas 5.

2. Immediately go to Layout at the top of your screen, and click on the dark arrow button:

Then select-Bottom Tree Anget Argled

3. Choose a symbol in the space provided on the left by simply clicking on the one you would like to use.

4. Then choose a connector by clicking on it with your mouse.

5. With your mouse, click anywhere on the screen and begin typing. When you are finished writing hit the ENTER button and your text should appear inside the symbol.

6. If you are unhappy with your symbol and or text you can always delete it by pressing the right-click button and selecting delete.

7. To edit your writing all you have to do is click on your symbol twice.

8. Once you have arranged your FLOW CHART into a logical order from raw materials/resources to the finished product, add your names to your work and select PRINT!

Hold on to your flow chart and hand it in at a later date. 
Appendix B: Sandra's lesson - teacher-created flowchart

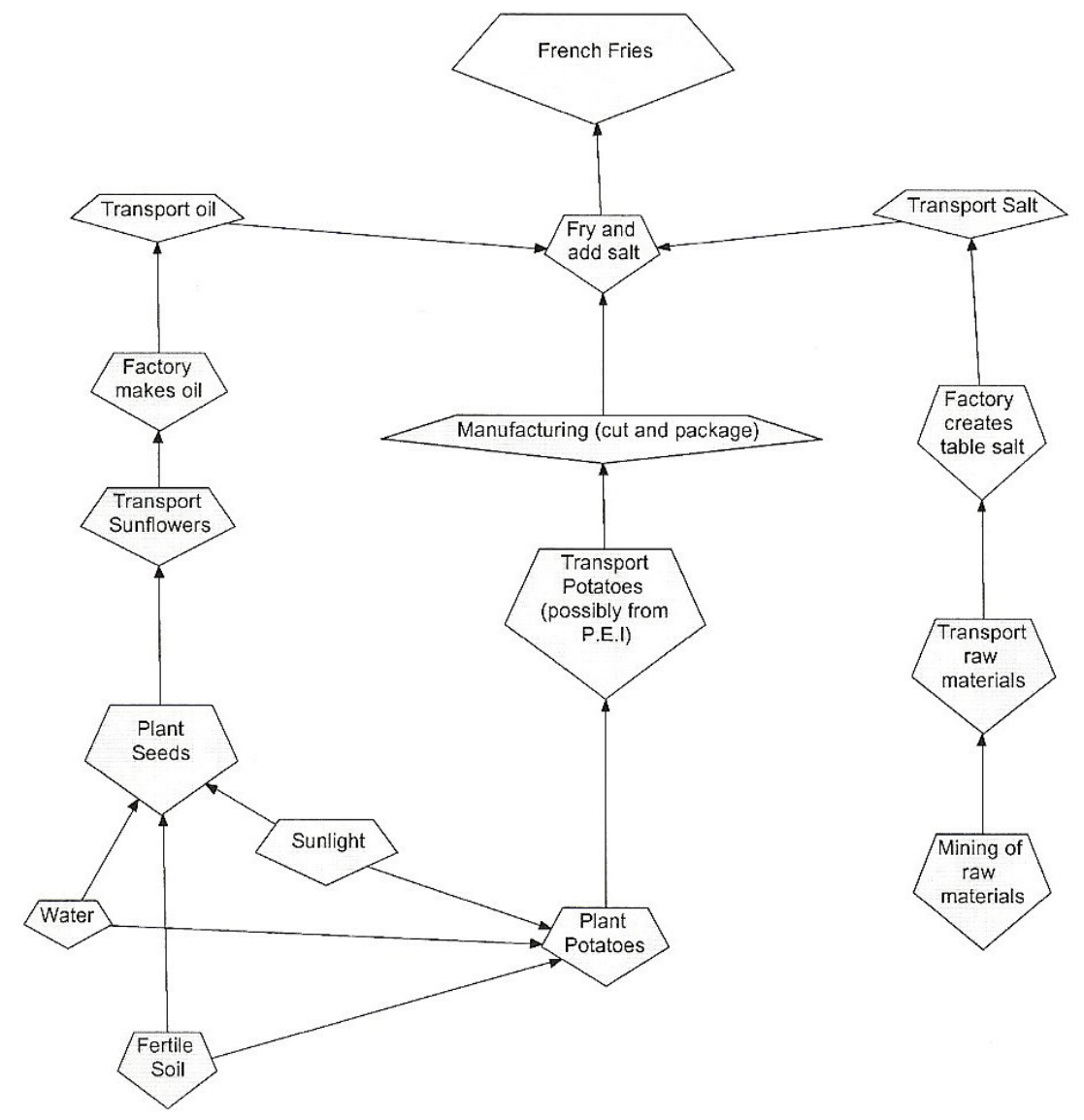


Appendix C: Chelsea's lesson teacher-created slideshow
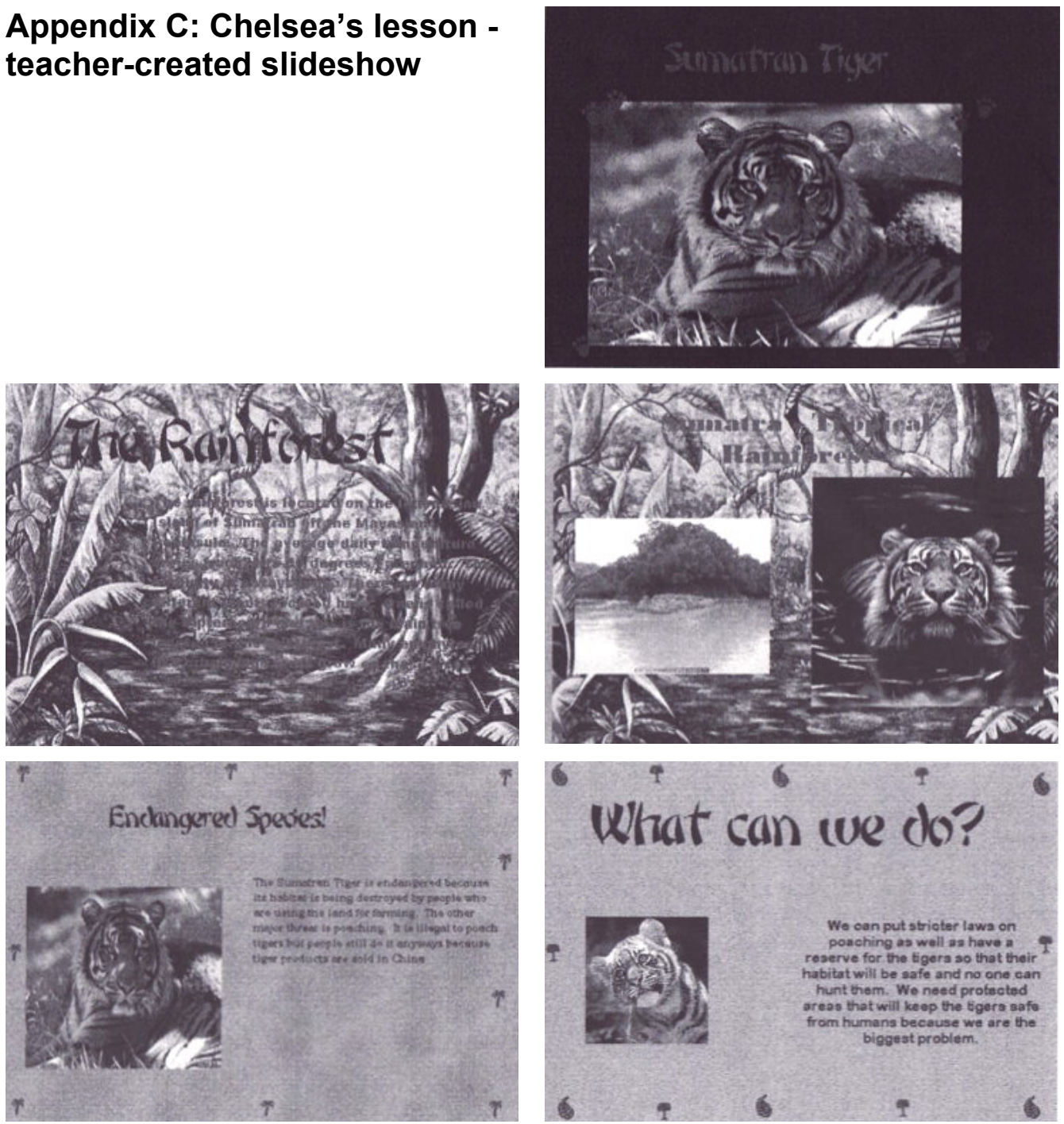


\section{Appendix D: Chelsea's lesson - page 2 of a two-page handout}

Click on File

- Click on Save As

- Give your slideshow a name. For example "Miss Dick's Slideshow"

- Click save

- Now you must go back to Paint Zone and create your next slide which should be why your animal is endangered

- Once you have finished your next slide (it tells you which one to do) you have to save your picture as another name. For example, Jonny 2

- Go back to the slideshow and your slides should be there from last time

- If not than go to File, then to Open

- Go to brockl, kidpix, users, guest, my pictures, my slideshow

- Click on your slideshow and click on open

- In the $2^{\operatorname{si}}$ box, click on the green box with the folder on it

- Open your next slide which is slide 2

- save your slideshow - Go to save as, click on the name of your slide show and press save

- When it asks you if you want to replace the filc, click yes

- Go back to Paint and create your next slide

- repeat the process over again with the saving and with loading your picture to the slideshow

Transitions

When all your slides have been saved on your slideshow, go to the left side of the screen where the film is with the red arrow on it. This is the slide transitions button

- This will make a time appear on the bottom of your slide as well as red arrows

- Click on the first arrow beside your first slide

- "Select Transition and Sound" pops up. This is where you decide how your slide will come onto the screen

- Select which ones you think you want. Click Preview to see what it looks like

- If you like it, click ok. If not choose different ones and preview again

- Next, click on the seconds button. Select one of the options and press ok

- Repeat this process for all of the slides

Viewing the slideshow

- When you want to view your finished slideshow, press the green play button on the left side of your screen

- After you have viewed it and you are happy, save it

- You are done!

Conclusion

computers 1. Students save theirpictures from the internet.

Reflection: 


\section{Appendix E: Chelsea's lesson - slide show handout}

\section{Elements of Slide Show}

This is what your slideshow should look like. These are the things that should be on each slide.

Slide 1 - The title page

- Put the name of your species on the first slide with a picture of your animal.

- At the bottom right hand corner of the slide put your name.

Slide 2

- A description of why your animal is endangered with a picture of the animal.

Slide 3

- Title - Habitat

- Picture of your animal's habitat and where your animal lives. Example, Rainforest

Slide 4

- Description of your animal's habitat. Example: Description of a rainforest

- $\quad$ It should include the temperature, rainfall, and plant life.

Slide 5

- What can be done to save your animal? You may put a picture in if you wish.

Slide 6

- An interesting fact about your animal.

- A picture of your animal.

Slide 7

- Your choice. You may whatever you want on this slide as long as it has to do with your animal.

- You may draw your own picture of your animal.

- You may put some more facts about your animal.

- It may be the ending slide of your slideshow.

Authors: Dr Candace Figg, Associate Professor, Teaching \& Learning with Technology Department of Teacher Education, Brock University

500 Glenridge Avenue, St. Catharines, ON L2S 3A1, Canada

Email: cfigg@brocku.ca Web: http:/ /www.figg.com/phd

Dr Kamini Jaipal-Jamani, Associate Professor, Department of Teacher Education Brock University, 500 Glenridge Avenue, St. Catharines, ON L2S 3A1, Canada Email: kjaipal@brocku.ca

Web: http:/ / www.brocku.ca/education/directory / teachered/kjaipal

Please cite as: Figg, C. \& Jaipal, K. (2011). Exploring teacher knowledge and actions supporting technology-enhanced teaching in elementary schools: Two approaches by pre-service teachers. Australasian Journal of Educational Technology, 27(7), 1227-1246. http: / / www.ascilite.org.au/ajet/ajet27/figg.html 